\title{
Teleseries y digitalización: ¿estrategia del medio para enfrentar la crisis?
}

\author{
Claudia Benassini Félix ${ }^{1}$ \\ Universidad La Salle, Ciudad de México
}

\section{RESUMEN}

El objetivo de este artículo es la caracterización de las series de televisión en el marco de la digitalización, particularmente desde los procesos de convergencia, transmedialidad y multipantalla para, en un segundo momento, reflexionar sobre las características de las nuevas audiencias en el marco de las nuevas modalidades de fruición. Finalmente, explora los parámetros del debate sobre la calidad del género y su eventual migración de "series" a "hiperseries".

Palabras clave: series, convergencia, transmedialidad, multipantalla, hiperseries, calidad

\section{ABSTRACT}

The main purpose of this article is the characterization of television series in the context of digitization, particularly from the processes of convergence, transmedia and multi-screen to, in a second moment, to reflect on the characteristics of the new audiences within the framework of the new modes of enjoyment. Finally, it explores the parameters of the debate on the quality of the genre and its possible migration from "series" to "byperseries".

Key Words: series, convergence, transmedia, multi-screen, hyperseries, quality

1Profesora Investigadora, Facultad Mexicana de Arquitectura, Diseño y Comunicación, Universidad La Salle, Ciudad de México. Titular del Grupo de Investigación "Alfabetización Digital, Transmedialidad y Gestión del Conocimiento". Correo electrónico: claudia.benassini@ulsa.mx 
Las últimas dos décadas se han caracterizado por un creciente debate sobre el futuro de la televisión. Una de las razones más importantes de este debate es producto de la convergencia tecnológica, que ha propiciado nuevas formas de crear, producir, distribuir y visualizar contenidos más allá de las opciones de la televisión abierta o de paga. En este contexto, plataformas como Netflix, Roku y Hulu, entre otras, han puesto a disposición de los usuarios contenidos de entretenimiento que los han liberado de los horarios rígidos y el consecuente acceso a estos contenidos de acuerdo con la lógica de la televisión. También se han ampliado las modalidades de acceso a estos contenidos: del aparato televisor que solía estar en la estancia familiar se ha pasado a la computadora — fija o laptop- así como a las tabletas, iPads y teléfonos inteligentes. En suma, la multiplicación de la oferta televisiva y sus posibilidades tecnológicas de acceso han contribuido a la crisis de la televisión, sobre todo en su modalidad abierta. ${ }^{2}$

Entre los dos extremos abiertos por el aumento en las plataformas y de los dispositi-

\footnotetext{
${ }^{2} \mathrm{Si}$ bien las estadísticas muestran un descenso en las suscripciones a la televisión de paga, ésta continúa siendo una opción para las audiencias, sobre todo por su oferta programática en géneros que - al menos por el momento- no están disponibles en otras plataformas, como los deportes y algunos concursos.
}

vos tecnológicos para la recepción se abre la oferta de contenidos televisivos. Igualmente, de manera creciente, se han incrementado las producciones que pretenden satisfacer a un público ávido de novedades, enmarcadas en ciertos parámetros de calidad que además satisfagan a perfiles tan diversos como los habituados a todas las formas de televisión, como los que se han formado en el marco de una relación creciente con las pantallas: desde el cine hasta el teléfono inteligente, pasando por las consolas de videojuegos.

Este trabajo se enmarca en los escenarios arriba descritos. Pretende caracterizar a las series y contextualizar su evolución reciente en los procesos de convergencia, transmedialidad y multipantalla para, en un segundo momento, reflexionar sobre las características de las nuevas audiencias en el marco de las nuevas modalidades de fruición. Las conclusiones se abren en dos vertientes: la primera, relacionada con este análisis, a propósito de la adaptación del género a estos procesos inherentes a la digitalización de la televisión. La segunda, abonar al debate sobre las perspectivas de la televisión, sobre todo desde la calidad y la eventual migración del género a hiperserie, en el marco de la reconfiguración del medio en un escenario de crisis. 


\section{LOS PROCESOS DE DIGITALIZA- CIÓN DE LA TELEVISIÓN}

\section{Convergencia}

$\mathrm{Al}$ definir a la convergencia como "el flujo de contenidos a través de múltiples plataformas mediáticas, la cooperación entre múltiples industrias mediáticas, y el comportamiento migratorio de las audiencias mediáticas, dispuestas a ir casi a cualquier parte en busca del tipo deseado de experiencias de entretenimiento", Henry Jenkins (2008, p. 14) sintetiza las correlaciones de la industria televisiva descritas en la Introducción a este trabajo. En este sentido, Roberto Igarza (2013, p. 24-25) indica que los nuevos escenarios de la convergencia están connotados por seis factores, entre los que cabe destacar: a) las intersecciones de plataformas horizontales y verticales; es decir, las posibilidades abiertas por la convergencia tecnológica, y b) la legitimidad social, cultural y económica de las industrias de los contenidos.

Con respecto a la convergencia tecnológica, Alfonso Gutiérrez Martín (2013, p. 90) hace hincapié en la forma en que la relación televisión-internet modifica la relación usuario-medio, a la vez que aumenta la interactividad. Beatriz Quiñones (2016, p. 70) añade que esta forma de convergencia incremente las posibilidades del usuario para elegir el momento y duración de su experiencia televisiva:

Esta posibilidad se engloba bajo un término originalmente comercial, el VOD, traducido como video a la carta. Desde que un archivo digital de video esté disponible en una plataforma mediada por un software y una interfaz semánticamente organizada (middleware), el usuario puede acceder a él en el momento que desee y verlo de la manera que quiera (seguido, por partes, devolver, adelantar, seleccionar, repetir). Esta característica de las videocasetes y el DVD es asumida por la TV digital y por la web. Servidores de contenido como YouTube o Vimeo apuntalan dinámicas cada vez más convencionales de hipervisualización de video que tienden a convertirse en el estándar, especialmente para los nativos digitales.

Asimismo, la convergencia tecnológica supone la interacción medios tradicionalesnuevos. De acuerdo con Henry Jenkins (2008, p. 17)

\footnotetext{
Ahora ha resurgido la convergencia como un importante punto de referencia, mientras las empresas mediáticas viejas y nuevas intentan imaginar el futuro de la industria del entretenimiento. Si el paradigma de la revolución digital presumía que los nuevos medios desplazarían a los viejos, el
} 
emergente paradigma de la convergencia asume que los viejos y nuevos medios interaccionarán de formas cada vez más complejas.

En este contexto, prosigue Jenkins (2008, pp. 26-27), "la convergencia tecnológica se alimenta por el cambio operado en los patrones de propiedad de los medios. Mientras el viejo Hollywood se centraba en el cine, los nuevos conglomerados mediáticos tienen participación mayoritaria en la industria del entretenimiento". Para el tema que nos ocupa, cabe recordar que la televisión ha evolucionado diacrónica y sincrónicamente de un sistema abierto con un número limitado de canales a diversos sistemas de distribución de la señal cuyas principales características son el pago de una suscripción y el incremento en la oferta programática.

Este proceso evolutivo ha estado relacionado tanto con el avance tecnológico como con la puesta al día de las necesidades del usuario. Beatriz Quiñones, (2016, p. 74) resume las nuevas características en conectividad, portabilidad e interactividad, que generaron un nuevo tipo de televidente que en este momento se posiciona en diversas partes del mundo. En este momento, el caso más emblemático de convergencia tecnológica es la progresiva incorporación de funciones en los
Claudia Benassini Félix

teléfonos móviles, que los han vuelto un dispositivo imprescindible para todas las actividades cotidianas, incluyendo la exposición a la televisión. Y si bien el teléfono móvil es el médium mediórum de nuestra época, las tabletas, iPads y computadoras nos ofrecen posibilidades similares de acceso (Ferrés, 2014, p 139140; Jenkins, 2008, p. 26).

A esta apretada descripción sobre los principales aspectos de la convergencia tecnológica y sus efectos en el usuario, es importante incorporar la conformación de grupos multimedia a nivel local y global, que han incidido en la implementación de tecnologías, así como en el incremento y mejoramiento de la oferta de contenidos, con miras a ampliar sus mercados y el consecuente número de adeptos. Este proceso se ha traducido en accesos desiguales de equipamiento y contenidos producto de la cadena de crisis económicas que desde hace años caracteriza al sistema mundial (Francés, 2015, p. 21). Este proceso, según Juan Piñón (2016, p. 41):

Es así que la industria de televisión se enfrenta a uno de los retos más colosales de su historia. Por un lado, la convergencia digital y la concentración mediática ha abierto nuevas oportunidades de relación de las audiencias, con una multiplicación de ventanas de distribución de contenidos, que 
los grandes conglomerados explotan a través de sinergias narrativas, con estrategias transmedia comerciales que consolidan universos completos bajo la idea de un programa o una idea como marca.

Por lo que se refiere a la legitimación de contenidos señalada por Igarza como un escenario de la convergencia, Joan Ferrés (2014, p. 142-143) argumenta que el proceso también puede abordarse desde el punto de vista cultural. Su observación resulta crucial antes de continuar, toda vez que da cuenta de los intereses de los grupos mediáticos de cara a posibles diálogos interculturales:

El concepto de convergencia se puede llevar más allá, ya que el nuevo entorno comunicativo representa una oportunidad única para el diálogo intercultural. Pero se trata sólo de una oportunidad. El simple hecho de tener informaciones procedentes de una gran diversidad de ámbitos culturales no garantiza el ensanchamiento de la conciencia, la apertura de miras o la instauración de diálogo entre culturas.

Al respecto, un análisis sobre cómo los contenidos televisivos contribuyen a la construcción del diálogo intercultural rebasa los objetivos de este texto, puesto que es un tra-
Claudia Benassini Félix

bajo que se ha venido realizando durante décadas. Un asunto en el que también parecen estar de acuerdo Jenkins (2008, p. 15): "las corporaciones, e incluso los individuos dentro de los medios corporativos, ejercen todavía un poder superior al de cualquier consumidor individual o incluso al del conjunto de consumidores. $\mathrm{Y}$ unos consumidores poseen mayores capacidades que otros para participar en esta cultura emergente". No deben perderse de vista las formas de organización de los usuarios a través de blogs y redes sociales para discutir abierta y críticamente los contenidos mediáticos (Gutiérrez Martín, 2013, p. 91-92).

\section{Transmedialidad}

De lo anterior se deduce que la convergencia tecnológica y entre contenidos conducen a nuevas formas de interactividad entre plataformas y contenidos: la transmediación. Yvana Fechine (2012, p. 196-198) propone emplear el término "para designar, de modo más amplio, toda producción de sentido fundada en la reiteración y familiaridad, omnipresencia y distribución en distintas plataformas tecnológicas (TV, cine, internet, celular, etc.) de contenidos asociados cuya articulación está anclada en la cultura participativa de los medios digitales". Desde esta perspectiva, continúa la autora, la transmediación puede ser pensada 
"como una de las lógicas de producción y recepción (consumo) de contenidos en escenario de convergencia".

Esta mirada a la transmedialidad permite vincular la actividad del usuario con los procesos de convergencia. Guillermo Orozco, Eva Navarro y Agustín García Mantilla (2012, p. 70) contribuyen a acotar este proceso en términos de la actividad del usuario:

Esta "transmedialidad" de la difusión y recepción por una parte y por otra, la creciente ubicuidad de las audiencias y su hiperconectividad, han reforzado la impresión de que el consumo mediático se ha vuelto automáticamente productivo al quedar bajo el control de los consumidores, internautas, videojugadores, cinéfilos y/o televidentes, etc., sin advertir siempre que en gran parte de los intercambios en el consumo son reactivos, sin que lleven a aparejada una reflexión previa y que no sólo por ser diferidos y transmediales, presenten necesariamente un germen de creación y relación horizontal.

Julio Cabero (2016, p. 5) añade que la transformación transmedia impulsada por el desarrollo tecnológico "está permitiendo al espectador del siglo XXI ver los programas televisivos decidiendo qué quiere ver, cómo y dónde desea hacerlo. No olvidemos, por una
Claudia Benassini Félix

parte, que una de las tendencias es hacia ver las emisiones de televisión en una segunda pantalla y que otra es la dirección de la televisión hacia dejar de ser un medio de comunicación de masas y dirigirse hacia su observación como medio individual". Como parte de este proceso, nos encontramos ante una "fragmentación añadida en donde el espectador consume contenidos desde diferentes plataformas", con el consecuente cambio en las estrategias de producción y difusión de contenidos audiovisuales para varias ventanas, incluso enriquecidos a través de formatos transmedia, con varias capas de lectura no lineal (Francés, 2015, p. 26).

En suma, la transmedialidad supone al menos tres procesos, vistos desde las nuevas lógicas de producción y difusión en escenario de convergencia (Fechine, 2012). El primero, la ubicuidad de los contenidos vía su visualización en diferentes pantallas, de acuerdo con las lógicas de consumo del usuario. Segundo, los procesos de construcción de sentido, producto de la omnipresencia de los contenidos en distintas plataformas, tanto televisivas como blogs y redes sociales. Tercero, transmite al usuario la decisión sobre qué quiere ver, a qué hora y dónde hacerlo. Estos tres procesos se relacionan con la lógica de producción y legitimación de las series de televisión, en es- 
cenarios de convergencia tecnológica y de contenidos, así como en el desarrollo de estrategias de construcción simbólica en contextos socioculturales más amplios.

\section{Multipantalla}

La convergencia tecnológica y la transmedialidad son el punto de partida para el análisis de la convergencia multiplataforma de la televisión, a partir de dos líneas estratégicas señaladas por Carles Lamelo (2016, p. 82). Primera, la llamada televisión a la carta, es decir, la distribución de contenido previamente transmitido por televisión: una práctica asociada a Netflix y Hulu. Segunda, la producción de contenidos netamente digitales para su distribución en línea, a través de diversas plataformas, como lo ha venido haciendo Netflix desde hace algunos años. Carlos Scolari (2014, p. 8) resume los cambios hasta aquí planteados, relacionados con la convergencia tecnológica y la televisiva:

Con el correr de los años, la televisión dejó de ser un tótem en el centro de la sala familiar. Primero las pantallas comenzaron a multiplicarse dentro del hogar (cocina, dormitorios), después pasaron a conquistar espacios públicos (bares, comercios, estaciones de trenes, aeropuertos, etc.) y finalmente se redujeron de tamaño hasta entrar en
Claudia Benassini Félix

nuestros bolsillos (a manera de teléfonos inteligentes, tabletas). La segunda pantalla del dispositivo móvil complementa y expande lo visto en la primera pantalla televisiva. Pantallas grandes, medianas y pequeñas. Pantallas para ver, pantallas para tocar. Primeras pantallas, segundas pantallas, pantallas globales. Las pantallas nos rodean.

En un trabajo previo (2017), dimos cuenta del interés que diversos autores han mostrado por analizar los fenómenos de convivencia entre pantallas. Esta reflexión nos llevó a hacer un análisis de cómo se ha desarrollado esta convivencia de manera diacrónica: cinetelevisión-videocasetera-videojuegos-

computadoras-tabletas-móviles, que han propiciado el desarrollo de estrategias de producción - hasta la transmedialidad - y distintas formas de relación e inmersión en el contenido por parte del usuario. Y un análisis sobre la convivencia sincrónica, es decir, la forma en que nuestras actividades cotidianas están circunscritas a la convivencia con dos o más pantallas mediante diversas combinaciones, dependiendo de estas actividades.

Somos audiencias transmediáticas: seleccionamos las pantallas para nuestras actividades cotidianas y podemos modificar la selección a nuestro gusto de acuerdo con nuestros intereses y necesidades. Sin embargo, la ubi- 
cuidad de la pantalla móvil la convierte en lo que, parafraseando a Guillermo Orozco y Darwin Franco, es una "pantalla todo terreno":

Ésta adquiere importancia dependiendo del tipo de uso preferente que se quiera hacer de ella; ya sea como dispositivo: 1) de comunicación; 2) convergente de medios y contenidos; 3) de ocio; 4) creación de contenidos multimedia; 5) organización. (Como ya veíamos en el uso de la computadora, los usos mayoritarios del teléfono móvil están concentrados en su capacidad como dispositivo de mera comunicación, pero, detrás de esta cifra, cada vez va adquiriendo mayor relevancia su capacidad como dispositivo convergente (Orozco y Franco, 2014: p. 107-109).

En suma, las posibilidades de convivencia con las pantallas son múltiples, aunque no infinitas; dependen de los intereses y posibilidades del usuario. Y sus combinaciones intervienen en los procesos de construcción de sentido. Estamos frente a un fenómeno de carácter polisémico, que se traduce en una múltiple combinación de los múltiples significados producto de los procesos de selección, combinación y exposición multipantalla. Una práctica con sus correspondientes implicaciones socioculturales dadas sus repercusiones en
Claudia Benassini Félix

nuestras actividades cotidianas. Y un fenómeno de fascinante abordaje para los estudiosos de fenómenos comunicativos.

\section{El escenario de la híper-televisión}

Durante los primeros años de la década de 1980 Umberto Eco dio a conocer su análisis sobre la evolución de la paleo y la neotelevisión. Más que una definición sobre el desarrollo del medio en Europa Occidental, la propuesta de Eco proporcionaba elementos para un análisis cualitativo sobre la evolución de la televisión en materia de lenguaje, crecimiento de la oferta, producción, relación con las audiencias y evolución de los géneros.

$\mathrm{El}$ análisis de Eco, publicado en La estrategia de la ilusión (1986, p. 200-203), fue la base para que otros estudiosos de la televisión siguieran su evolución de acuerdo al desarrollo de estas categorías, desde la post-televisión o meta-televisión, a partir de la última década del siglo XX. La multiplicación de la oferta televisiva incluyendo plataformas digitales, la convergencia tecnológica y de contenidos, así como los escenarios de competencia e interactividad fueron los nuevos elementos que se incorporaron al análisis (Riera, 2003; Tous, 2009).

En este contexto, Carlos Scolari (2008, p. 2) ha destacado la importancia cualitativa de la 
audiencia: no es lo mismo conquistar a la que se ha formado desde los medios tradicionales —radio, prensa y televisión- "que producir programas para nuevas generaciones con competencias interpretativas generadas en experiencias hipertextuales como la navegación en la web, el uso de software o los videojuegos”. Más adelante, (p. 5) propone el término hipertelevisión, "para definir el estado actual del dispositivo televisivo. Este concepto no deberá ser visto como una nueva fase de la serie paleo/neo televisión (...) sino como una particular configuración de la red sociotécnica". Como puede observarse, este enfoque de Scolari se corresponde con la mirada de Beatriz Quiñones a propósito de las opciones de selección de la oferta televisiva por parte del usuario.

La propuesta de Scolari conduce a la adaptación del género Series a un escenario de convergencia, transmedialidad y multipantalla, caracterizado por modificar la práctica del broadcasting al narrowcasting y al singlecasting. Se trata de cambios en el consumo televisivo, acompañados de nuevos parámetros de calidad en el marco de una creciente competencia por las audiencias, en el contexto de un número creciente de plataformas que han modificado el modelo de negocios de la televisión, que se presenta además como una tendencia a continuar por los siguientes 15 o 20 años. Hecha esta síntesis necesaria, pasamos a un análisis de la evolución de las series para cumplir con el objetivo principal de este trabajo.

\section{SERIES: CONVERGENCIA, TRANS- MEDIALIDAD Y MULTIPANTALLA AL SERVICIO DEL GÉNERO Y DEL USUARIO}

La admiración por estas series no hace más que aumentar, igualando, léase superando, la que despiertan las películas de cine, lo que hace que las series, igual que las películas, se vean en formato DVD. En la época de la telepantalla, las series de culto, siguiendo los pasos de los antiguos folletines, desarrollan su sucesión de episodios y se multiplican con sus seguidores y su público de todo el mundo; en Internet se les dedica multitud de páginas en que se detallan sus éxitos más sonados (Giles Lipovetsky y Jean Serroy, 2009, p. 224-225)

La referencia de Lipovetsky y Serroy define el escenario sobre el que actualmente se desarrollan las series de televisión. Un escenario en el que conviven en diferentes formas con el usuario en virtud de la convergencia tecnológica y narrativa, la transmedialidad que favorece las relaciones entre medios y sus contenidos contribuyendo a la construcción de 
sentidos, y la multipantalla, que confiere ubicuidad al género, de tal forma que la fruición puede llevarse a cabo prácticamente en cualquier lugar. A continuación presentamos una síntesis sobre la evolución del género, que busca ubicar sus momentos relevantes sobre todo durante las tres últimas décadas. Por razones de espacio, los nombres se presentan únicamente cuando es necesario. Finalmente cabe destacar que los autores consultados coinciden en ubicar a Estados Unidos como la cuna de las series, desde donde se habría exportado a diversas partes del mundo, en un proceso que dista mucho de concluir, tanto por su expansión como por la búsqueda de la calidad del género.

\section{Definición: de Los intocables a Hill Street Blues}

Los autores consultados (Cascajosa 2015; de la Torre, 2016; Brett, 2014) coinciden al ubicar el origen de las series en Estados Unidos. Según Concepción Cascajosa (2015, p. 90-91):

La expresión "serie de televisión" ha venido a significar un relato audiovisual fragmentado que se comercializa a través de un aparato televisor en una estructura de programación. A pesar de todos los vaivenes experimentados en los últimos años, la mayor parte del público sigue viendo las
Claudia Benassini Félix

series mientras son emitidas en su pase original, que se mantiene como primera ventana de exhibición de igual forma que las películas más populares y de mayor prestigio siguen llegando por primera vez a los espectadores a través de las salas de cine.

De esta definición se desprende la relevancia que mantiene la televisión como medio de comunicación, puesto que —abierta o de paga, dentro o fuera del país de origen - es la primera opción para exposición al género; es decir, se mantienen los criterios de convergencia entre contenidos y posteriores usos multipantalla. Asimismo, los tres autores coinciden en señalar que, a diferencia de lo que sucedió en otros países, los orígenes de la televisión en Estados Unidos no corresponden al directo, sino a la televisión filmada. Nuevamente Cascajosa (2015, pp. 125-126):

A final de los cincuenta (la televisión), pudo por fin convertirse en un objeto de consumo para las clases medias, y muy pronto también para las populares. A nivel de programación, en casi todos los países se produjo un proceso parecido a la adopción de fórmulas de ficción, con la mayor parte de los recursos económicos dedicados a la producción de antologías dramáticas. Pero el salto de las series necesitaba de un soporte indus- 
trial más complejo y autosuficiente y por ello las cadenas europeas, en muchos casos hasta aquellas situadas al otro lado del Telón de Acero, encontraron en las series norteamericanas un contenido barato (para) ofrecer a sus espectadores miles de horas de entretenimiento.

Con estos antecedentes, los tres autores consultados dan cuenta de la evolución de las series, cuyos ejes temáticos fueron concentrándose en situaciones propias de la clase media norteamericana, de interés eventual para otros países en los que eran exhibidas. Por razones de espacio y de objetivos no es posible extenderse mucho en estas décadas. Sin embargo, también hay coincidencia en señalar a Hill Street Blues (El precio del deber) como un parteaguas en el género, en un momento en que la NBC — la cadena productora y exhibidora - ocupaba el tercer lugar en audiencia detrás de CBS y ABC. Toni de la Torre (2016, pp. 725-726) relata que Fred Silverman, ejecutivo de la NBC, concibió la idea de una serie policiaca con importantes diferencias con respecto a la forma en que hasta entonces se había manejado el género.

Este concepto ya marca una distancia respecto a ficciones anteriores, pues pone el acento en el lado humano de los protagonistas, convirtiéndolos
Claudia Benassini Félix

en el núcleo de la ficción, y la esencia de la serie se aparta de las habituales concepciones en las que el gancho reside en el carisma de un protagonista de características singulares o bien en la vuelta de tuerca respecto al género de una premisa original.

La trama giraba en torno al capitán Frank Furillo y su equipo de colaboradores, y daba cuenta de sus conflictos personales o en el trabajo. El mismo de la Torre (2016, pp. 724725) señala que Silverman autorizó una segunda temporada de la serie, por considerarla un referente de la televisión de prestigio que quería dar a la cadena.

Semanas después de firmada la renovación se anunciaron los candidatos a los Emmy y Hill Street Blues obtuvo catorce nominaciones en las categorías de series dramáticas. De golpe, una serie que salía prácticamente de la nada era coronada como la ficción de referencia. Hill Street Blues, además, reunía unas características en su resultado final y en su gestación que la diferenciaban del resto de ficciones de la época y marcaron un punto de inflexión en la forma de entender y escribir las series contemporáneas.

De la Torre añade que la estructura de Hill Street Blues se ha convertido en el formato 
estándar de la narración serial. Para Martin Brett (2014, p. 61 y ss), la serie era el ideal platónico de lo que definiría a la televisión de calidad.

Retrataba el lugar de trabajo como sustituto del entorno familiar. Combinaba drama y comedia. El argumento, desarrollado por múltiples personajes, hacía referencia a temas sociales y políticos. Al mismo tiempo, el estilo visual de la serie granulado e hiperrealista, con la cámara en constante movimiento y una banda sonora llena de sonidos superpuestos - mostraba los rasgos de la recién acabada década del nuevo cine norteamericana.

El éxito de Hill Street Blues coincide con el momento del despegue de la televisión por cable en Estados Unidos. En esta década los suscriptores se incrementan de manera considerable, con las consecuencias para la televisión abierta. Según Martin Brett (2014 p 69. 70)

...las cifras que habían determinado el éxito de un mundo con sólo tres cadenas, se estaban reduciendo drásticamente. Un programa podía triunfar con muchos menos ojos. Es más, las cadenas se estaban volviendo cada vez más sofisticadas a la hora de medir la calidad de esos ojos en
Claudia Benassini Félix

lugar de limitarse a contarlos. En vez de tratar de atraer a una tercera parte de todos los telespectadores (lo cual, en cualquier caso, era cada vez más imposible), las cadenas se centraban en grupos demográficos específicos: ricos, jóvenes, cualificados, etc. La fragmentación de la audiencia estadounidense había empezado. Y como sucedería de nuevo veinte años más tarde, se trataba de algo positivo para la televisión de calidad.

En ese momento, la televisión por cable inició la oferta de canales especializados tanto en deportes - ESPN- y noticias, como CNN.

Y también en la década de 1980 se popularizó el uso de videograbadoras, que permitieron a las audiencias grabar los materiales de su preferencia y reproducirlos en el momento que quisiera.

\section{"No es televisión, es HBO"}

En 1972 Charles Dolan, fundador de Cablevisión en Estados Unidos, concibió la idea de un servicio Premium de televisión por cable centrado en deportes y películas.

El nombre inicial de Canal Verde fue sustituido por Home Box Office y así fue vendido al grupo Time Inc. (Brett, 2014, p. 100). El lema seleccionado fue el inicio de un cambio que buscaba atraer televidentes fieles, más allá 
de las ocasionales películas o eventos deportivos. John Bewkes, entonces presidente del canal, buscó su fortalecimiento a través de dos estrategias: la reinvención de $\mathrm{HBO}$ como marca y la inversión en series de producción propia (Brett, 2016 p 985-986).

Toni de la Torre (2016, p. 992) lo resume de la siguiente manera:

Las series de HBO tendrán en común el énfasis en la narración serial y los arcos argumentales, en oposición de los episodios auto-conclusivos, más comunes en las cadenas, de manera que exigirán a la audiencia una mayor disciplina en el visionado. La popularidad de las ediciones en DVD de las series (el formato se lanzó al mercado en 1997 y fue adquiriendo un papel cada vez más importante en el consumo audiovisual) facilitará que el público pueda mantener esta disciplina y al mismo tiempo popularizará la idea, hace años impensable, de que la serie es una producción digna de ser conservada y coleccionada.

Sex and the City (1998), Los Soprano (1999), Carnival (2003), True Blood (2008) y Game of Thrones (2011) son algunos nombres de la larga lista de producciones que $\mathrm{HBO}$ ha lanzado al aire durante los últimos veinte años.

Para de la Torre (2016, pp. 988-989) la cadena fue instrumental en la creación de la percepción social de que las series merecían ser consideradas como obra de arte y, en consecuencia, la aproximación a las mismas debía ser similar a la de otros fenómenos culturales.

Lo que hace que un determinado objeto sea considerado arte no se encuentra en el objeto mismo, sino en la perspectiva de la sociedad en que éste se produce (...). Al etiquetar su propia ficción como un valor cultural superior, $\mathrm{HBO}$ creó el colectivo (es decir, sus suscriptores) que estaban de acuerdo con la afirmación inicial. Paulatinamente, y a lo largo del nuevo milenio, esta consideración trascenderá las barreras de HBO y se extenderá a otras series con intenciones parecidas a las del canal, pero no amparará nunca la televisión en su totalidad, de manera que la ficción serial llegará a ser considerada como un artefacto artístico que se produce dentro de un medio de masas que no es considerado como tal.

Cabe añadir que tanto los productores de Hill Street Blues como los directivos de $\mathrm{HBO}$ tuvieron clara la idea de la reivindicación del autor.

Esta política se tradujo en una mayor oferta de guionistas interesados en participar en proyectos de la cadena televisiva, así como en una reivindicación de las producciones televisivas de cara a las cinematográficas. 


\section{Cine-televisión: la calidad de las series}

Los hechos que hasta aquí se han sintetizado apretadamente condujeron a un asunto debate sobre la calidad del cine y la televisión, presente a lo largo de al menos seis décadas. Martin Brett (2014, pp. 21-22) recupera del tema elementos relacionados con la narración.

De hecho, la televisión siempre se ha comparado de manera reflexiva con el cine, pero esta forma de narración continuada y sin final definido estaba por utilizar una comparación habitual, más próxima a las novelas victorianas por entregas, otra explosión de alta cultura en un medio popular vulgar. Aquella revolución también se había visto favorecida por convulsiones relacionadas con la forma de crear, producir, distribuir y consumir historias (...) Como en el caso de la nueva televisión, las mejores novelas por entregas — de Dickens, Trollope o George Elliot- generaban suspenso a lo largo de la obra en lugar de tratarse de simples episodios emocionantes.

Toni de la Torre (2016, pp. 994-995) también selecciona la narrativa, aunque con énfasis en la participación del guionista en televisión, retomando la experiencia de HBO.

Lentamente fue instalándose la idea de que la televisión era el medio en el que el guionista tenía
Claudia Benassini Félix

el papel más importante y del que surgía la visión artística de cada proyecto, mientras que en el cine este poder estaba en manos del director. Por supuesto, nada de esto hubiera funcionado si $\mathrm{HBO}$ no hubiera traducido sus intenciones con series que pusieran en la pantalla todas estas ideas.

Por su parte, de la revisión de diversos actores Concepción Cascajosa apunta que el atractivo de las series se deriva de un procedimiento estético en el que la forma — visual y narrativa - está intrínsecamente ligada a un nuevo tipo de contenido. La autora recupera cuatro características de las series del semiótico francés Vincent Colonna: a) sujetos y/o géneros narrativos jamás vistos en la televisión; una narración compleja, lejos del demasiado fácil y desperdigado relato televisual lineal; c) una imagen trabajada como en el cine y d) una transgresión moral de los tabúes más establecidos de la cultura de la pequeña pantalla (en Cascajosa, 2015, p. 21).

Como puede observarse, estas tres posiciones claramente destacan la narración. Es clara la importancia creciente que el autor/guionista tiene para los productores de series, que desemboca en el llamado showrunner, concepto reciente que designa a las mentes creativas que hacen posible las ficciones que tanto interés despiertan en las audiencias, 
generalmente a la cabeza del equipo de producción (de la Torre, 2016, p. 1228; Newman y Levine, 2012, p. 134). Esta argumentación será clave en las diversas formas que irá cobrando la serie televisiva y en los cambios introducidos en distintos momentos para dar pie a publicidad, para evitarla y para que las audiencias vean varios capítulos —si no es que una temporada completa- en una sola sesión.

\section{Los cambios en la audiencia}

Este artículo se inicia con la crisis que desde hace varios años atraviesan la televisión abierta y por cable, evidenciada sobre todo por la pérdida de audiencia, que se ha desplazado hacia otras opciones. En este sentido, para Concepción Cascajosa (2015, pp. 39-40) las innovaciones tecnológicas, lejos de terminar con el contenido televisivo, son un factor determinante para una nueva relación entre los espectadores y las series.

Las ediciones en DVD y BluRay, las descargas de Internet, los grabadores digitales y las plataformas de televisión de pago permitieron desligar el contenido televisivo de la parrilla tradicional y en algunos casos hasta del mismo aparato. $\mathrm{Al}$ igual que con una película o un libro, las series de televisión ya se pueden consumir al gusto del espec-
Claudia Benassini Félix

tador, como y cuando quiera. Y en comparación con otros productos culturales, esta nueva modalidad de consumo tenía sentido en términos de economía doméstica.

En apartados previos hicimos algunos señalamientos sobre la presencia de estas tecnologías en la evolución de las series. Corresponde ahora hacerlo en relación con la evolución de las audiencias de series; y si bien Cascajosa argumenta que la primera exposición se lleva a cabo en los canales de origen, en este momento es necesario considerar las disponibilidades multicanal para que las audiencias accedan a las series. Previo a su clasificación de las audiencias, Carles Lamelo (2016, p. 182202) ofrece los siguientes argumentos, que ubican al género y sus audiencias dentro de la híper-televisión caracterizada por Scolari:

- La ficción televisiva es uno de los géneros que mejor se han adaptado a la narrativa transmedia. Fundamenta su continuidad en el registro de audiencias y en su capacidad para crear comunidad en torno a unos personajes y una trama principal.

- La necesidad de mantener en vilo a los seguidores hasta el siguiente capítulo ha orillado a los creativos a realizar contenidos audiovisuales de valor aña- 
dido, que han evolucionado en transmedia.

- En la actualidad, la disponibilidad de productos del género dificulta que los seguidores mantengan su fidelidad a determinadas tramas. La nueva fragmentación de las audiencias promueve la producción de historias más arriesgadas y seriales de culto muy orientados a públicos menos numerosos, pero muy interesantes para las cadenas por su capacidad de consumo en términos publicitarios y su influencia en comunidades digitales y fuera de línea. ${ }^{3}$

- Las series traspasan ya las fronteras de la televisión lineal para acercarse de manera irremisible a extensiones en la web a través de webisodios y perfiles en las redes sociales; esta extensión vive nuevas fases con la proliferación de productos mediáticos tales como podcast, narraciones radiofónicas, galerías de imágenes, listas musicales, etc. El universo crece y se expande buscando nuevas vías de negocio como los videojuegos, libros, cómics y juegos de

${ }^{3}$ Aunque el resultado no necesariamente conduzca a buen término, a juzgar por la reciente decisión de Netflix (mayo de 2017) de cancelar Sense8, una serie que aparentemente tenía una buena aceptación por parte de las audiencias.
Claudia Benassini Félix

mesa. La interrelación dramática de cada una de estas nuevas ventanas es lo que determina si estamos ante un producto transmedia, multimedia o crossmedia.

- Los creadores de contenidos deben tener en cuenta que un alto porcentaje de internautas accederán a sus videos en línea sin ejercer de prosumidores y que otros seguirán la serie a la carta sin extender su consumo a otros productos comunicativos e incluso quienes solamente la verán en línea sin sumarse a la emisión reglada en la programación televisiva. Por este motivo, cada vez más programadores tienen en cuenta las audiencias digitales y la influencia 2.0 de sus contenidos para tomar decisiones estratégicas.

A partir de estos argumentos y apoyado en la tipología de Mar Guerrero, Lamelo ofrece la siguiente clasificación sobre la evolución de las audiencias:

\begin{tabular}{|l|l|}
\hline PRINCIPIANTES & $\begin{array}{l}\text { Un visitante casual } \\
\text { de la web o un fan } \\
\text { novato cuya partici- } \\
\text { pación en el sitio } \\
\text { supone una disposi- }\end{array}$ \\
\hline
\end{tabular}




\begin{tabular}{|c|c|}
\hline & $\begin{array}{l}\text { ción favorable a } \\
\text { sumergirse progresi- } \\
\text { vamente en la narra- } \\
\text { tiva de la serie y en } \\
\text { sus extensiones } \\
\text { transmedia. }\end{array}$ \\
\hline MEDIOS & $\begin{array}{l}\text { Aquel fan que toda- } \\
\text { vía carece de un } \\
\text { conocimiento ex- } \\
\text { haustivo, pero que } \\
\text { detenta competen- } \\
\text { cias siempre superio- } \\
\text { res al del principian- } \\
\text { te, lo que le permite } \\
\text { consumir contenidos } \\
\text { que están fuera de la } \\
\text { posición semiótica } \\
\text { de este último. }\end{array}$ \\
\hline AVANZADOS & $\begin{array}{l}\text { Un fan veterano o } \\
\text { experto en cuanto a } \\
\text { la amplitud de sus } \\
\text { competencias inter- } \\
\text { pretativas que lo } \\
\text { habilitan para un } \\
\text { aprovechamiento } \\
\text { intensivo de todos } \\
\text { los contenidos ofer- } \\
\text { tados por la web. }\end{array}$ \\
\hline
\end{tabular}

Perfil de usuarios de webs de series de TV (Mar Guerrero en Lamelo, 2016:205)
Cabe precisar que, para efectos de este trabajo, esta clasificación es la que ofrece los indicadores sobre la forma en que evolucionan las audiencias de series diacrónicamente y sincrónicamente hablando. ${ }^{4}$ Es decir, sin importar la edad y otros datos propios de los perfiles, la exposición al género, la conversación entre afines y la consulta de materiales adicionales van refinando estos cambios.

De hecho, da cuenta de diversas formas de participación e interacción de los usuarios. Lamelo (2016, pp. 209-210) incluye en su análisis a los usuarios consumidores de segunda pantalla, que "interactúan con contenido vinculado temáticamente en un cuerpo de contenido común. Es decir, consumimos un programa de televisión lineal y lo comentamos en redes sociales o bien buscamos información adicional en Internet u otras fuentes".

En un segundo momento, las tipologías de usuarios y audiencias evolucionan en comunidades de fans que, vía el trabajo colaborativo, comparten contenidos, además de abrir espacios para la discusión de tramas y personajes en blogs y redes sociales.

${ }^{4}$ Tanto Lamelo como otros autores proporcionan otras tipologías que dan cuenta de la actividad de las audiencias prosumidoras en la producción y circulación de contenidos transmediáticos derivados de la exposición al género. 
Concepción Cascajosa (2015, pp. 385386) afirma que el fenómeno de los fans no es reciente, aunque el nuevo contexto televisivo las ha revalorizado, pues de ser únicamente compradores potenciales de productos asociados a la serie,

...su potencial de consumo es mucho más importante para un modelo de serie que no puede apelar a un público masivo y que necesita de las ediciones domésticas y los ingresos asociados al merchandising para tener sentido en términos económicos. El desarrollo de la cultura de las series ha tenido que ver con el establecimiento de unas particulares prácticas de consumo. La disociación entre el contenido televisivo y el aparato televisor ha multiplicado los mecanismos para ver series, de forma que el contexto casero y el entorno familiar no ha desaparecido, pero convive con el visionado en solitario, en pareja y en grupos de amigos y lugares tan heterogéneos que incluye las salas de cine en estrenos de temporadas y eventos especiales.

Este acercamiento a la evolución de las audiencias nos permitirá relacionarlas con la evolución de las series y con su papel en la construcción de la transmedialidad.

Por lo pronto, anticipamos una de las relaciones que se establece con lo que Lamelo y otros autores denominan segunda pantalla, utilizado en este caso como complemento a la exposición de los contenidos.

\section{Valor económico, publicidad y ritmo de las series \\ Para Concepción Cascajosa (2015, p. 105), es difícil simplificar el valor económico de las series en un entorno cada vez más comple- jo...}

...y su valor fundamental es, junto con lograr un número apreciable de espectadores, ayudar a configurar la identidad de marca de la cadena para aumentar su visibilidad, focalizar las campañas publicitarias y servir de elemento de arrastre para el resto de la programación. No es lo mismo configurar esa identidad para un canal orientado a mujeres, a afroamericanos, a hombres jóvenes o a adolescentes.

Este aspecto es muy importante, ya que cuando las series son transmitidas a través de un sistema Over The Top - como Netflixpierden la identidad del canal que les dio origen, para ser conocidas genéricamente por el nombre de la plataforma que dio continuidad a la popularidad previamente construida. La misma autora (2015, pp. 67-68) afirma que la realidad económica demuestra que los ingre- 
sos publicitarios de las series -incluso las más exitosas en cuanto a espectadores- casi nunca van a cubrir la licencia de emisión que deben pagar a sus productoras, aunque la situación es diferente para la televisión abierta y para las cadenas de cable:

Tradicionalmente, las cadenas han abonado a las productoras de las series una licencia de emisión que pudiera ser rápidamente amortizada con la venta de anuncios, ofreciendo una rentabilidad perfectamente cuantificable en términos económicos para los programas de éxito. Pero para las cadenas de cable establecer el beneficio económico de los programas es mucho más complejo, ya que la manera en la que contribuyen a construir su idea de marca opera a medio y largo plazo. Dentro de un mercado en el que los espectadores pueden elegir entre cientos de opciones diferentes, las series originales son el principal contenido que da prestigio a los canales y ayuda a fidelizar la audiencia si existe una fuerte sintonía entre el contenido de la serie y la programación media del canal.

Como puede observarse, la autora reitera la importancia de la fidelización de las audiencias, como una variable relevante para identificar a la cadena responsable de la producción y/o transmisión de la serie, más allá de si se trata de una cadena abierta o de cable. En este contexto, independientemente de su calidad o de los niveles de audiencia, las series producidas y exhibidas por televisión abierta están obligadas a los cortes publicitarios como principal fuente de sostenimiento. Estos cortes cuatro en una hora- determinan también el ritmo de la serie, que está supeditada a estas interrupciones. Sin embargo, la pérdida de audiencias a consecuencia de las nuevas modalidades de consumo televisivo se tradujo en una baja en las tarifas publicitarias, que obligó a las cadenas a sumar un corte adicional a los cuatro previos. Así lo explica Toni de la Torre (2016, p. 1129-1130):

$\mathrm{ABC}$ fue la primera cadena en tomar medidas ante este problema, y en la temporada 2004-05 decidió introducir una pausa publicitaria más en cada uno de los episodios de las series, de manera que se modificó la estructura de los cuatro actos vigente desde los años sesenta para pasar a una estructura de cinco actos. Este cambio se introdujo en las series de $\mathrm{ABC}$ estrenadas en otoño de 2004 (Lost, Esposas desesperadas y Anatomía de Grey), todas producidas por ABC Studios en colaboración con otras productoras. Como la duración de un episodio siguió siendo la misma, el cambio también redujo el tiempo de cada acto, que unido al añadido de un punto de giro más, hizo que el 
ritmo narrativo aumentara. El cambio tuvo éxito, pues las tres series fueron muy populares en la cadena, y permitió introducir más publicidad, compensando el descenso de las tarifas. En 2006 ABS Studios introdujo una nueva estructura de seis actos que estableció como plantilla de todas las producciones del estudio y fue adoptada también por NBC Universal Televisión Studio, que producía series para NBC pero también para Fox, como Doctor House, una de las primeras en incorporar esta estructura, que comprimió todavía más la duración de cada acto (ahora alrededor de los ocho minutos cuando había sido de doce minutos).

De la Torre (2016, p. 1131) añade que estos cambios llevaron a los guionistas a la introducción de más puntos de giro, con la consecuente dificultad para crear escenas con resonancia dramática, que ahora debían alcanzarse más rápidamente. Los canales por cable no tenían estas limitaciones, como tampoco las tenían sus creadores en este sentido. De la Torre añade (2016, p. 990) que la ausencia de publicidad en las cadenas de televisión por cable acercaba al espectador a una percepción más parecida a la del cine:

Además, sumerge al espectador en una experiencia de visionado distinta, sin interrupciones, que
Claudia Benassini Félix

lo predispone a la contemplación y a la observación estética de las series, detectando sus valores culturales, identificando la mirada del autor que tienen detrás, apreciando los significados existentes más allá de la historia que se desarrolla y reconociendo las referencias culturales y las relaciones con otros géneros y medios narrativos. En otras palabras, invita a las audiencias a acercarse a la serie de televisión de una forma más cercana a la que tiene lugar cuando observamos un cuadro en un museo que a la que tenemos cuando hacemos zapping entre las diversas cadenas.

Como puede observarse, la necesidad de allegarse de recursos económicos ha determinado la forma de narrar la trama de las series, en el caso de la televisión abierta. Un elemento adicional, presente desde los primeros años del género, fue la exportación internacional, que también se traducía en dividendos económicos.

A ella se acogieron con más fuerza tras la popularización de las videocaseteras y las grabadoras de video digital (DVR, por sus siglas en inglés), que permitía a las audiencias saltarse las pautas publicitarias (de la Torre, 2016, p. 1128-1129). Como ya no podía garantizarse que los anuncios tuvieran el mismo impacto, descendieron las tarifas, con las consecuencias arriba descritas. 
Pero la introducción del DVR hacia finales del siglo XX no solo tuvo repercusiones en las tarifas publicitarias. También repercutió en la baja percepción del espectador hacia la competencia entre cadenas y canales por cable: si nunca había sido relevante, en este momento pasó a ser insignificante:

Esta tecnología permitía que cada espectador pudiera hacerse una programación a medida, seleccionando qué contenidos quería que el aparato almacenara. De esta manera, la fidelidad a una cadena que había distinguido al mundo de la televisión en la era de los programadores se estaba perdiendo (...). En vez de elegir su ventana de contenidos favorita y seguir su programación, el espectador del DVR seleccionaba los contenidos que quería ver, que podían ser de diferentes canales, creando una programación propia con series de orígenes diversos. El programador había perdido importancia como prescriptor, y las cadenas y canales veían cómo su marca se diluía... (de la Torre, 2016, pp. 1132-1133).

El uso del DVR con estos propósitos contribuyó también a la búsqueda de internacionalización de las series. Adicionalmente, se trata de un primer movimiento que conduce a la audiencia a seleccionar su programación para verla en los tiempos y horas de su predi- lección. Faltaban unos años para que a este proceso se aunaran las posibilidades abiertas por las nuevas plataformas y la evolución de las pantallas.

\section{Over the Top: conquista de la convergen- cia}

Hasta aquí hemos soslayado las posibilidades de que las series dejen de verse en el espacio doméstico destinado exprofeso para la televisión y de ahí haya pasado a otros lugares vía la adquisición de más de un equipo. Asimismo, durante los primeros años del siglo XXI Internet comienza a poblarse de contenidos televisivos: desde páginas corporativas, grupos de discusión, producciones de usuarios que pronto encontraron su nicho en You'Tube, experimentos aislados en webnovelas y webseries, espacios educativos y repositorios de contenidos diversos. Toni de la Torre (2016, pp. 1305-1306) resume que para 2007

...la emergencia de Internet como una nueva ventana llevó a las cadenas a intentar posicionarse en este nuevo mercado. El proyecto más destacado en este sentido fue la creación de Hulu, un servicio bajo demanda creado por Disney, Comcast y News Corporation que permitía ver los contenidos de tres grandes cadenas como $\mathrm{ABC}$, NBC y Fox de forma gratuita y bajo demanda, 
pero siempre tras la emisión original, dentro del territorio de Estados Unidos (para no perder las ventas internacionales, que habían adquirido una gran importancia en los beneficios de las cadenas) y con publicidad para obtener un rendimiento en el proceso.

Diez años antes, en 1997, nació Netflix, como un servicio de videoclub que se presentaba como alternativa a propuestas como Blockbuster. La propuesta, fundada por Reed Hastings y Marc Randolph, creció vía el envío de materiales a domicilio y posteriormente el servicio por streaming, gracias a la convergencia entre televisión y computadora. En 2007, coincidiendo con la llegada de Hulu, decide concentrarse en el último servicio, primero en Estados Unidos y después en otros países. Toni de la Torre (2016, pp. 1306-1308) añade que Netflix llegó a acuerdos con los grandes conglomerados —incluidos los fundadores de Hulu - para incorporar a su catálogo todo tipo de contenidos, incluyendo series de televisión. Esta opción para la transmisión de contenidos vía la cesión de derechos implicó un nuevo modelo de negocio.

Para las cadenas era un paso lógico en ese momento, pues retenían los derechos de la primera emisión, manteniéndose como la primera ventana
Claudia Benassini Félix

de distribución, y obtenían beneficios de la emisión en la segunda ventana en una estructura similar a la del mercado de la sindicación, y también de la cesión de derechos de las temporadas anteriores de sus series, que para los servicios de VOD suponía un aumento vertiginoso del número de títulos de su catálogo y para el espectador una mejora sustancial en la disponibilidad de las series (de la Torre, 2016, pp. 1308-1309).

Según Concepción Cascajosa (2015, pp. 90-91), "el cambio tecnológico ha llevado a redefinir lo que es un exhibidor televisivo gracias a la mayor capacidad de las líneas de banda ancha y la posibilidad que ofrecen de hacer llegar un contenido con alta calidad de imagen casi instantáneamente a los usuarios". Para Toni de la Torre (2016, pp. 1312-1313), el daño colateral fue la diversificación de la atención del espectador.

Para los servicios de VOD, esta competencia entre usuarios para ver todos los episodios posibles es positiva porque aumenta el consumo y solidifica la importancia del servicio en sus vidas (disminuyendo la posibilidad de una baja en la suscripción). Pero también es beneficioso para las cadenas. Al fin y al cabo, cuando todos los episodios de una serie se terminan, la primera ventana de emisión de los nuevos episodios sigue encon- 
trándose en la televisión, así que es probable que cuando se estrene la nueva temporada, el espectador acuda a la cadena. De hecho, es posible que una serie se haga popular a través de los servicios de VOD sin que haya sido un éxito en la televisión. Aunque no suele ser lo más habitual, servicios como Netflix tienen tendencias propias no relacionadas con lo que sucede con la industria televisiva que surgen del sistema de recomendación y del intercambio de opiniones de la comunidad, y que pueden alterar el recorrido de una serie (De la Torre, 2016, pp.1312-1313).

Por su parte, Juan Piñón (2016, p. 40) añade las ventajas de Netflix frente a $\mathrm{HBO}$, su principal competidor:

En particular, el éxito de suscripción de Netflix, el cual surgió ofreciendo un innovador servicio de películas en DVD vía correo postal, evolucionó en un par de años a una biblioteca totalmente digitalizada y el acceso a casi toda su librería por servicios de streaming. Siguiendo los pasos de $\mathrm{HBO}$, y dado que su modelo de negocio está sustentado en su larga base de suscriptores, Netflix no tendrá las limitaciones de negociar con anunciantes o restricciones de las leyes sobre obscenidad, desnudo o profanadas y, al igual que HBO, podrá abordar temas controversiales con una mirada innovadora en sus más famosas series.
Claudia Benassini Félix

Mientras HBO Go lanzada en el 2010, permitía a los suscriptores del canal acceso digital a su programación por diferentes plataformas digitales, el lanzamiento de HBO Now a finales del 2014 permitirá al público suscribirse a la arena, sin siquiera tener la necesidad de contratar cable (Piñón, 2016, p. 40).

Como puede observarse, estas afirmaciones concuerdan con la tendencia del espectador a ver las series en el canal de televisión correspondiente, a la vez que constituyen un primer acercamiento hacia las formas en que se mueven los usuarios de sistemas como Netflix.

Otro problema se relacionaba con la identidad de marca. De la Torre y Cascajosa coinciden en afirmar que la función de las series de ficción es contribuir en este sentido:

Las series ayudan a popularizar el canal entre los abonados potenciales y servir así como atractivo complemento al señuelo de las promociones para captarles como clientes y, luego, son un elemento de continuidad en parrillas conformadas por películas, documentales y eventos deportivos, favoreciendo la fidelidad a su programación (Cascajosa, 2015, pp. 69-70).

Para de la Torre (2016, pp. 1321-1322), 
...las series de los distintos canales que pasaban a formar parte de Netflix quedaban disociadas de su fuente de origen. Al tener series de éxito en plataformas en las que no se identificaba la marca principal, esta perdía valor de forma inevitable. HBO había capitalizado el éxito de series como The Sopranos y Game of Thrones haciendo crecer su prestigio y popularidad. Si estas series se veían en otras plataformas en las que no estaba presente el nombre HBO, éste se diluía. Reforzar la propia marca y distinguirla del resto era particularmente relevante para el negocio de la televisión por cable, que, como hemos visto, vende a sus suscriptores el concepto entero del canal más allá de series concretas. En cambio, Netflix vende la facilidad de acceso a todas las series, no en una línea editorial concreta, y por ello le conviene eliminar la presencia de la marca de origen de las ficciones presentes en su catálogo.

Este escenario motivó a HBO y a Fox a buscar su propio servicio, en vez de continuar cediendo las licencias a Netflix, que desde 2011 incursiona exitosamente en las producciones propias. House of cards, Orange is the new black, 13 reasons, entre las más identificadas, se suman a los acuerdos alcanzados con México y España para producciones locales: Club de cuervos y Las chicas del cable, respectivamente. En este contexto, Cascajosa (2015, p. 96) y de
Claudia Benassini Félix

la Torre coinciden al afirmar que Netflix maneja una gran cantidad de datos — Big Datasobre sus usuarios que sus ejecutivos no están dispuestos a compartir.

Actividades, plataforma seleccionada, búsquedas en internet, gustos y horarios son concentrados en enormes bases de datos, cuyos resultados derivarían en el mejoramiento de las series. Pero la empresa ha sido tan hermética que ni siquiera ha dado a conocer los datos sobre sus producciones propias, incluyendo el uso del Big Data.

Netflix había estado usando los hábitos y afinidades de los suscriptores desde hacía años, pues es esta información la que utiliza el sistema automático de recomendaciones del servicio, de elevada efectividad (según la compañía, un 75 por ciento de los visionados de Netflix se originaban a partir de la recomendación del algoritmo o de la recomendación de otro usuario de Netflix). Hasta entonces nadie se había cuestionado si era correcta la utilización de esta información, pero en el momento en que se utilizaron para intentar determinar qué proyectos de series podían tener éxito surgieron críticas alegando que los procesos creativos no deberían estar condicionados por estos datos. Sin embargo, el uso de estos no era muy diferente de los estudios de mercado y los grupos focales, entre otras herramientas de uso 
muy extendido en el mundo de Hollywood y otro tipo de industrias. La gran diferencia es que los datos que maneja Netflix son extraordinariamente detallados, mucho más que la información que pueden tener los canales tradicionales, y también que el uso que se hace de estos datos es opaco. Es decir, que Netflix no desvela qué factores tiene en cuenta y para qué los tiene en cuenta (de la Torre, 2016, pp. 1331-1332).

Actualmente, los suscriptores de Netflix tienen a su disposición un catálogo que incluye series y películas, que además se actualiza mensualmente.

El modelo de negocio ha encontrado repetidores, aunque no tienen el mismo éxito, sobre todo porque no han logrado trascender las fronteras locales; es el caso de Hulu, que continúa en Estados Unidos, Blim de Televisa en México y Claro, de Carlos Slim, cuyos servicios de ubican en distintos países de América Latina, entre ellos México.

Asimismo, la producción de series se ha diversificado: aunque Estados Unidos sigue siendo el país pionero en producción y distribución, Alemania, Francia, Inglaterra y España se han lanzado a la caza de un mercado a todas luces redituable, y por el momento utilizando la plataforma de Netflix.
Claudia Benassini Félix

Ciertamente, Netflix se ha convertido en un importante canal para la difusión de las teleseries, particularmente en un segundo ciclo de distribución, como ya se comentó. Un canal que, por monto de producción, privilegia las series norteamericanas, pero que también se ha convertido en un importante escaparate para que las audiencias se acerquen a las producciones hechas en otros países como España, Inglaterra, Francia, Chile, Argentina y México, entre otros.

Los propósitos más importantes de estos ciclos de circulación son de índole económica, como también se ha planteado. Sin embargo, como se verá en las conclusiones, revisten importancia en la redefinición de los parámetros de calidad del género mismo y, eventualmente, de la ficción.

\section{CONCLUSIONES}

\section{Entre la calidad, la legitimación y las hi- perseries}

A lo largo de este artículo hemos intentado mostrar las implicaciones de la digitalización de la televisión desde los procesos de convergencia, transmedialidad y multipantalla entre el medio y el usuario con la hipermediación de las series. 
Hacemos dos observaciones al respecto: la primera, retomando a Cascajosa en el sentido de que los avances tecnológicos se han traducido en un acercamiento de los contenidos al usuario. Un proceso que se inicia en la década de 1980 — justo en el segundo auge del género- con las videocaseteras, y que seguirá con el DVD y el DVR como opciones que permiten al usuario tomar distancia del medio y construir otra relación con los géneros. Una relación que ha encontrado un importante momento en las opciones Over The Top, cuyo desarrollo apenas se inicia.

La segunda observación se refiere a los cambios en la relación que las audiencias construyen con los contenidos televisivos, que dan lugar a clasificaciones como la propuesta por Carles Lamelo. Clasificaciones que, debe advertirse, tienen un carácter provisional, toda vez que son producto de primeras indagaciones que parten de las características del género para, en un segundo momento, trabajarlas con las audiencias/prosumidores.

$\mathrm{Al}$ respecto, cabe destacar que - por los objetivos del artículo- muy poco se enfatizó sobre la relación que las audiencias y prosumidores mantienen con los contenidos de las series a través de blogs y redes sociales, ya sea de las propias televisoras, productoras de contenido o generados por los usuarios.
Claudia Benassini Félix

La apropiación de los contenidos es tema de una investigación aparte, aunque consideramos pertinente comentarlo a estas alturas del texto, en el marco de los futuros trabajos a realizar sobre el tema. $\mathrm{Al}$ igual que la tipología de las audiencias y las nuevas relaciones con los contenidos abiertas por la tecnología, es preciso documentar los hallazgos desde otras metodologías que den cuenta de semejanzas y diferencias mediadas por la tecnología, los contenidos mediáticos, la interacción social y las redes sociales.

Desde otra perspectiva, a principios de la década de 1980 — tras el éxito de Hill Street Blues- los críticos de la televisión comenzaron a hablar sobre la calidad del medio. Concepción Cascajosa (2015, p. 140) cita a Robert J. Thompson, quien en 1997 publicó el libro La segunda edad dorada de la televisión, en cuyo prefacio menciona doce características de su calidad, que más adelante fueron utilizados como una guía para la valoración crítica de las series no sólo en Estados Unidos, también en Francia, Inglaterra y España. ${ }^{5}$

${ }^{5} \mathrm{El}$ libro puede consultarse en Google, las doce características están en la Introducción (p. 12-17): Es televisión no convencional (al estilo de $\mathrm{HBO}$ ); sus productores han tenido experiencia en otros medios como el cine; atrae a una audiencia urbana y sofisticada; logra limitadas audiencias y debe luchar por la supervivencia en el brutal mercado de la televisión comercial; tiene un reparto variado de actores; recurre a la memoria de 
Gran parte de estas características ha sido descrita en los apartados previos. En este contexto, Newman y Levine (2012, p. 18-37) dan cuenta del largo camino recorrido por la televisión en busca de su legitimación. Los autores reconocen que desde sus orígenes en los primeros años de la década de 1950 el medio fue cuestionado tanto por sus deficiencias tecnológicas - que se traducían en mala calidad - como por el atractivo que ejercía en las masas. La llegada del cable y la convergencia tecnológica - continúan Newman y Levinehan propiciado la búsqueda por la calidad del contenido y los cambios en la forma de ver televisión.

Por su parte, Julio Cabero (2016:55) afirma que "la calidad de los programas televisivos puede estar asociada a la diversidad de opciones de comunicación (formatos, lenguajes, etc.), la pluralidad de los contenidos y el tratamiento narrativo de las temáticas. También es cierto que la simple combinación de estos elementos no garantiza la calidad de los programas, y en ello influyen fuertemente las características y preferencias del espectador". A la convergencia tecnológica aducida por

los espectadores; se basa en la hibridación de géneros; se basa en el trabajo del escritor; es autoconsciente y referencial; tiende a la controversia y explora tópicos progresistas; aspira al realismo y logra una apreciable repercusión crítica materializada en premios.
Newman y Levine, añadimos el papel que Cabero confiere al usuario, lo que nos remite nuevamente a la revisión de las audiencias y a profundizar en el debate sobre la legitimación de la televisión a través de la calidad de sus contenidos en un trabajo posterior. ${ }^{6}$

Una última reflexión se refiere a la migración de las series a hiperseries, en un sentido similar a las contribuciones de Thomson al debate sobre la calidad. Jesús Arroyave, catedrático de la Universidad del Norte, ubica esta posibilidad partiendo de Hill Street Blues, en la llamada segunda época dorada del género. Basa su propuesta en la narrativa, solidez de los personajes y manejo cinematográfico, así como con la relación que construyen con las audiencias. Una relación adictiva que puede conducir a consumir una temporada completa en una sesión: el llamado binge-watching. Aun cuando Arroyave apenas soslaya su propuesta, es pertinente relacionarla con la caracterización de Scolari (2008, pp. 5-6) de la hípertelevisión: dirigida a un usuario con ciertas características y a partir de la configuración sociotécnica del medio. Una caracterización que incluye también a las series en cuanto a su

'Son muchos los académicos que han contribuido a este debate desde el análisis del género en ámbitos como la política, la narrativa, la intertextualidad y la referencialidad. El aquí mencionado trabajo de Ana Tous abona en este sentido. 
estructura y narratividad que nos haría pensar que hacia allá se encamina el género "series".

Una última reflexión sobre la crisis por la que atraviesa la televisión, tanto abierta como de paga, aunque en la mirada de los grandes grupos mediáticos que mantienen el control de la televisión a nivel local y global, sin alternativas de solución a mediano y largo plazo. Son contados los casos que a estas alturas han buscado modificar su modelo de negocio, o desarrollado estrategias de producción de contenidos multiplataforma, o implementado espacios para la participación de las audiencias a través de las redes sociales. Gabriel Torres (2016, p. 162-164) analiza cada uno de estos escenarios, concluyendo que —así como la conocemos en este momento- la televisión abierta desaparecerá en unos años. Otros analistas señalan que la toma en directo - que caracterizó a la televisión en sus inicios- se mantendrá en espacios informativos, así como en eventos deportivos y especiales, mientras que la televisión de paga tendría que cambiar su modelo a un esquema más personalizado que no considere prioritario el acceso a docenas de canales desde el centro del hogar.

En este contexto, Gabriel Torres coincide con otros analistas de la televisión, en el sentido de que la televisión de hoy es el modelo everywhere: en un ambiente hiperconectado, a través de dispositivos interactivos y polifuncionales, construido desde diversas pantallas, dispositivos tecnológicos y comunidades de audiencias prosumidoras, con nuevos formatos y modos de distribución Over the Top y el Big Data como programador (Orozco, 2015, p. 80; Piscitelli, 2015, p 148-152). Un modelo al que hasta ahora las series parecen haberse adaptado, en gran parte debido a su formato. Continúan los trabajos que buscan reconfigurar otros géneros a las necesidades del everywhere. La televisión abierta aún no toca fondo, a la vez que se abre un amplio panorama para otras modalidades hipermediadoras con el usuario y las opciones abiertas por la digitalización del medio. 


\section{FUENTES CONSULTADAS}

Arroyave, J. (2014). "La TV que veremos: de las series a las hiperseries", en El Heraldo, Colombia, 19 de enero, recuperado el 5 de abril de 2017, http://revistas.elheraldo.co/latitud/la-tv-que-veremos-delas-series-las-hiperseries-129830.

Benassini, C. (2017). "Multipantalla: mediador entre los YouTubers y la transmedialidad", ponencia presentada en el XXXVIII Encuentro Nacional de Investigadores de la Comunicación, Universidad de Guanajuato, abril de 2017.

Brett, M. (2014). Hombres fuera de serie, Madrid, Editorial Ariel.

Cabero, J. (2016). "La vieja televisión, ¿es la nueva televisión? los nuevos espectadores”, en Orozco, G. (coordinador) TVMorfosis 6, México, Edit. Tintable.

Cascajosa Virino, C. (2015). La cultura de las series, Barcelona, Edit. Laertes.

De la Torre, T. (2016). Historia de las series, Barcelona, Roca Editorial Libros.

Eco, U. (1986). La estrategia de la ilusión, Barcelona, Edit. Lumen.

Fechine, Y. (2012). "Transmidiacâo, entre o lúdico e o narrativo": 175-210, en Campalans, C., Renó D. y Gosciola, V. (editores académicos) Narrativa Transmedia: entre teorías y prácticas, Bogotá, Colección de textos de Ciencias Humanas, Editorial del Rosario.

Ferrés i Prats, J. (2014). Las pantallas y el cerebro emocional, Barcelona, Edit. Gedisa.

Francés, M. (2015). "La digitalización de los contenidos audiovisuales en el espacio global. Convergencias y desigualdades", 21-31, en Orozco, G. (coordinador), TVMorfosis 4, México, Edit. Tintable.

Gordillo, I. (2009). La hipertelevisión: géneros y formatos, Quito, Colección Intiyán, Ediciones de CIESPAL.

Gutiérrez Martín, A. (2013). "Televidentes en red-dados: educación mediática para usuarios interactivos", en Orozco, G. (Coordinador), TVMorfosis 2, México, Edit. Tintable, 87-106.

Igarza, R. (2013). "El rescate de las mediaciones a la hora transmedia", en Orozco, G., (coordinador), TVMorfosis 2, México, Edit. Tintable, 13-25.

Jenkins, H. (2008). Convergence culture; la cultura de la convergencia de los medios de comunicación, Barcelona, Edit. Paidós.

Lamelo, C. (2016). Televisión Social y Transmedia: nuevos paradigmas de producción y consumo televisivo, Barcelona, Edit. UOC.

Lipovetzky, G. y Serroy, J. (2009). Pantalla Global, Barcelona, Edit. Anagrama. 
Newman, M. y Levine, E. (2012). Legitimating Television, Nueva York, Edit. Routledge.

Orozco, G., Navarro, E. y García Mantilla, A. (2012). "Desafíos educativos en tiempos de autocomunicación masiva: la interlocución de las audiencias”, en Comunicar, núm. 38, XIX, 67-74.

- y Franco, D. (2014). Al filo de las pantallas, Buenos Aires, La Crujía Ediciones. . (2015), “Televisión Everywhere”, en Orozco, G. (coordinador), TVMorfosis 4, México, Edit. Tintable, 7-10.

Piñón, J. (2016). "Las series de televisión como estrategia de la industria dentro de la convergencia digital”, en Orozco, G. (coordinador), TVMorfosis 6, México, Edit. Tintable, 29-47.

Piscitelli, A. (2015). “¿La nueva televisión es la vieja televisión? De las arquitecturas de la libertad a las arquitecturas de control", en Orozco, G. (coordinador), TVMorfosis 4, México, Edit. Tintable, 147161.

Quiñones, B. (2016). “Los nuevos escenarios de la televisión”, en Orozco, G. (Coordinador), TVMorfosis 6, México, Edit. Tintable, 63-78.

Riera, F., (2003). "La Post-televisión: de la televisión antropológica a la sociedad digital”, en Cuadernos del $C A C$, Consejo Audiovisual de Cataluña, número 15, enero-abril, 93-96.

Scolari, C., (2008). "Hacia la hipertelevisión. Los primeros síntomas de una nueva configuración del dispositivo televisivo", en Diálogos de la Comunicación, núm. 77, julio-diciembre, 1-9.

. (2013). "La televisión, los libros y la feria. Si no puedes vencerlos, únete a ellos (y pásate al transmedia)", 27-36, en Orozco, G., (coordinador), TVMorfosis 2, México, Edit. Tintable.

Tous Rovirosa, A. (2009). "Paleotelevisión, neotelevisión y metatelevisión en las series dramáticas estadounidenses”, en Comunicar, núm. 33, vol. XVII, 175-183. 